\title{
Kinetics, Isotherm and Thermodynamic Studies of the Adsorption of Reactive Red 239 Dye from Aqueous Solution by Chitosan 8B
}

\author{
Subarna Karmaker, Farin Sintaha, Tapan Kumar Saha* \\ Department of Chemistry, Jahangirnagar University, Savar, Bangladesh \\ Email: ^tksaha_ju@yahoo.com
}

How to cite this paper: Karmaker, S., Sintaha, F. and Saha, T.K. (2019) Kinetics, Isotherm and Thermodynamic Studies of the Adsorption of Reactive Red 239 Dye from Aqueous Solution by Chitosan 8B. Advances in Biological Chemistry, 9, 1-22. https://doi.org/10.4236/abc.2019.91001

Received: December 4, 2018

Accepted: January 1, 2019

Published: January 4, 2019

Copyright () 2019 by author(s) and Scientific Research Publishing Inc. This work is licensed under the Creative Commons Attribution International License (CC BY 4.0).

http://creativecommons.org/licenses/by/4.0/

(c) (i) Open Access

\begin{abstract}
The adsorption of reactive red 239 (RR239) dye onto chitosan 8B was studied in aqueous solution at various $\mathrm{pHs}$, initial dye concentrations, ionic strengths and temperatures, respectively. The adsorption of dye onto chitosan $8 \mathrm{~B}$ was confirmed by diffuse reflectance electronic absorption spectra. The adsorption of RR239 onto chitosan 8B was greatly influenced by solution pHs, initial dye concentrations, ionic strengths and temperatures. The kinetics and mechanism of dye adsorption process were analyzed by pseudo first-, second-order, Elovich and intraparticle diffusion kinetic models. The adsorption kinetics of RR239 dye followed a pseudo second-order model very well. The surface sorption and intraparticle diffusion mechanisms were involved in the actual sorption process. The equilibrium isotherm data were fitted well with the Langmuir model rather than the Freundlich, Temkin and Dubinin-Radushkevich models. The maximum dye adsorption onto chitosan $8 \mathrm{~B}$ was estimated to be $163.93 \mu \mathrm{mol} / \mathrm{g}$ at $45^{\circ} \mathrm{C}$. The activation energy $\left(E_{\mathrm{a}}\right)$ was obtained to be $23.30 \mathrm{~kJ} / \mathrm{mol}$. The computed thermodynamic parameters such as $\Delta G^{\ddagger}, \Delta H^{*}, \Delta S^{\ddagger}, \Delta G, \Delta H$ and $\Delta S$ confirmed that the adsorption of RR239 dye onto chitosan $8 \mathrm{~B}$ was a spontaneous endothermic physisorption process. Desorption test was carried out in $\mathrm{NaOH}$ solution ( $\mathrm{pH}$ 12.5) and the chitosan flakes could be reused.
\end{abstract}

\section{Keywords}

Chitosan, Reactive Red 239, Adsorption, Kinetics, Mechanism, Thermodynamics

\section{Introduction}

Rapid industrialization has led to increased various types of pollutants into aq- 
uatic systems that have been identified as among the main causes of environmental pollution and degradation. Dyes, which are widely used in different industries, can impede light penetration into water, retard photosynthetic activity, inhibit the growth of biota and have a tendency to chelate metal ions [1]. Accordingly, the treatment of colored dye effluent streams has been attracted the attention of environmentalists, technologists, and entrepreneurs because of its socioeconomic and political dimensions. Almost one million tons of dyes are annually produced in the world, of which azo dyes, characterized by an azo bond $\left(\mathrm{R}^{1}-\mathrm{N}=\mathrm{N}-\mathrm{R}^{2}\right)$, represent approximately $70 \mathrm{wt} \%$ [2]. Azo dyes are the most common synthetic colorants released to the environment by textile, paint, varnish, paper, plastic, food, pharmaceutical, and cosmetic industries. The release of azo dyes in aquatic environment is challenging not only for aesthetic reasons but also because azo dyes and their cleavage products (aromatic amines) are carcinogenic [2] [3]. Numerous technologies, such as adsorption [4] [5] [6] [7], membrane filtration [8], coagulation [9], ozonation [10], advanced chemical oxidation [11] [12], and biological processes [13], have been developed and applied worldwide for the scavenging and/or degradation of dyestuff wastewater.

The adsorption process is an efficient method for the removal of dyes from effluent due to its low initial cost, simplicity of design, ease of operation and insensitivity to toxic substances. Activated carbon is the most widely used as an adsorbent due to its large surface area, microporous structure and high adsorption capacity [14]. However, its use is limited due to its high cost. Therefore, the use of low-cost, easily obtained, high-efficiency and eco-friendly adsorbents has been investigated as an ideal alternative to the current, more expensive methods for removing dyes from wastewater [15]. A number of reports on the application of low cost adsorbents to eliminate reactive dyes from aqueous solution appeared in literatures [16]-[22]. Chitin and its partially deacetylated derivative chitosan are biocompatible and biodegradable polymers. Chitosan have large numbers of amine and hydroxyl functional groups (Figure 1(a)). These functional groups are very effective and promising to isolate toxic heavy metals from aqueous solution [23] [24]. The opportunity of utilizing chitosan as a biosorbent to eliminate azo dyes from aqueous solution has also been taken into significant consideration [17] [25] [26] [27] [28] [29]. However, the related reports on utilizing chitosan to remove the reactive red 239 (RR239; Figure 1(b)) azo dye from aqueous solution are comparatively insufficient.

The aim of this study was to examine the ability of chitosan $8 \mathrm{~B}$ (80\% deacetylated chitin) as a low cost adsorbent to separate reactive red 239 (RR239) from aqueous solution. The influences of significant aspects, such as solution pHs, initial dye concentration, ionic strengths and temperatures on RR239 adsorption onto chitosan $8 \mathrm{~B}$ were studied in batch mode. The potential rate controlling step and adsorption mechanisms were analyzed by several kinetic equations (i.e., pseudo first-, pseudo second-order equations, Elovich and intraparticle diffusion models). Freundlich, Temkin, Dubinin-Radushkevich and Langmuir adsorption 
isotherms were applied to compute the adsorption equilibrium. Activation and apparent thermodynamic parameters were also evaluated.

\section{Experimental}

\subsection{Materials}

Katokichi Bio Co., Ltd., Japan provided chitosan 8B (80\% deacetylated chitin) which was used without further purification. A laser scattering particle size analyzer (LDSA-2400A, Tonichi Computer Applications, Japan) equipped with a dry dispersing apparatus (PD-10S, Tonichi Computer Applications, Japan) was used to determine the particle size of chitosan $8 \mathrm{~B}$. The mass median diameters of the chitosan $8 \mathrm{~B}$ flakes were found to be $247 \pm 9 \mu \mathrm{m}$.

Reactive red 239 (RR239; Figure 1(b)) dye was obtained from Sigma-Aldrich, Germany and was utilized without further purification. Other reagents used in the present work were analytical grade. Deionized water was prepared by circulating distilled water through a deionizing column (Barnstead, Syboron Corporation, Boston, USA).

\subsection{Spectroscopic Measurements}

For spectroscopic measurements, the samples were prepared by mixing solid RR239, chitosan 8B, and chitosan 8B flake-RR239 complex with solid $\mathrm{KBr}$. The diffuse reflectance electronic absorption spectra of solid samples were recorded by a Varian, Cary 5000 UV-visible-NIR spectrometer (Varian Inc., USA) in the wavelength region of $200-800 \mathrm{~nm}$.

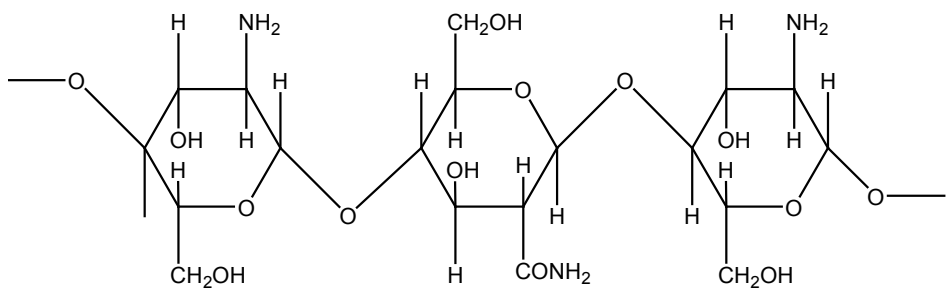

(a)<smiles>O=[S+](O)c1cc2cc(S(=O)(=O)O)cc(Nc3nc(Cl)nc(Nc4ccc(S(=O)(=O)O)cc4)n3)c2c(O)c1/N=N\c1ccc2c(S(=O)(=O)O)cccc2c1S(=O)(=O)O</smiles>

(b)

Figure 1. The structure of (a) chitosan 8B and (b) reactive red 239 (RR239). 


\subsection{Batch Adsorption Experiments}

Batch adsorption experiments were conducted with slight modifications of previously described method for the adsorption of reactive yellow 145 (RY145) onto chitosan in aqueous solution [26]. The adsorption of RR239 onto chitosan 8B was explored in $125 \mathrm{~mL}$ stoppered bottles containing a fixed amount $(0.05 \mathrm{~g})$ of chitosan $8 \mathrm{~B}$ with $25 \mathrm{~mL}$ of dye solution $(100 \mu \mathrm{mol} / \mathrm{L})$. The primary $\mathrm{pH}$ of the dye solution was adjusted with $1 \mathrm{~mol} / \mathrm{L} \mathrm{HCl}$ or $1 \mathrm{~mol} / \mathrm{L} \mathrm{NaOH}$ solution. The $\mathrm{pH}$ of dye solution was measured by using a $\mathrm{pH}$ meter (HANNA instruments microprocessor $\mathrm{pH}$ meter). The stoppered bottles were shaken in a thermostated shaker at room temperature $\left(30^{\circ} \mathrm{C} \pm 0.2^{\circ} \mathrm{C}\right)$ with a speed of $120 \mathrm{r} / \mathrm{min}$ until reaching equilibrium. Each bottle was capped to avoid evaporation at high temperature. Samples were withdrawn at predetermined intervals of time for analyzing the concentration of RR239 in solution. The samples were centrifuged using a centrifuge machine (Labofuge 200, D-37520 Osterods, Germany) at a speed of $4000 \mathrm{rpm}$ for $5 \mathrm{~min}$. The concentration of RR239 in the supernatant was determined by spectrophotometric methods using a Shimadzu UV-1601PC spectrophotometer (Shimadzu, Japan) at $\lambda_{\max }$ value of $541 \mathrm{~nm}$. The $\lambda_{\max }(541 \mathrm{~nm})$ of RR239 solution was found to be constant at the pH ranges between 4 and 10 . The apparent molar absorptivity of RR239 was estimated to be $15 \times 10^{3}$ $\mathrm{L} / \mathrm{mol} / \mathrm{cm}$ at $541 \mathrm{~nm}$ and $\mathrm{pH} 4-10$.

The amount of RR239 adsorbed onto chitosan $8 \mathrm{~B}$ at time $t, q_{t}(\mu \mathrm{mol} / \mathrm{g})$ was determined by

$$
q_{t}=\frac{V\left(C_{0}-C_{t}\right)}{m}
$$

where $C_{0}(\mu \mathrm{mol} / \mathrm{L})$ and $C_{t}(\mu \mathrm{mol} / \mathrm{L})$ are the liquid-phase concentrations of RR239 at initial and any time $t$, respectively; $V(\mathrm{~L})$ is the volume of RR239 solution and $m(\mathrm{~g})$ is the amount of dry chitosan $8 \mathrm{~B}$ used.

The adsorption kinetics was also performed varying initial concentration of dye solutions $(30-200 \mu \mathrm{mol} / \mathrm{L})$, ionic strengths $(0.01-0.04 \mathrm{~mol} / \mathrm{L})$ and temperatures $\left(30^{\circ} \mathrm{C}, 35^{\circ} \mathrm{C}, 40^{\circ} \mathrm{C}\right.$ and $\left.45^{\circ} \mathrm{C}\right)$, respectively. The ionic strength of dye solutions was adjusted with $1 \mathrm{~mol} / \mathrm{L} \mathrm{Na}_{2} \mathrm{SO}_{4}$ solution. The equilibrium adsorption was carried out at four different temperatures $\left(30^{\circ} \mathrm{C}, 35^{\circ} \mathrm{C}, 40^{\circ} \mathrm{C}\right.$ and $\left.45^{\circ} \mathrm{C}\right)$, and at $\mathrm{pH} 4$ in absence of $\mathrm{Na}_{2} \mathrm{SO}_{4}$.

The amount of RR239 adsorbed onto chitosan $8 \mathrm{~B}$ at equilibrium time, $q_{e}$ $(\mu \mathrm{mol} / \mathrm{g})$ was determined by

$$
q_{e}=\frac{V\left(C_{0}-C_{e}\right)}{m}
$$

where $C_{e}(\mu \mathrm{mol} / \mathrm{L})$ is the liquid-phase concentrations of RR239 at equilibrium time; $C_{0}, V$ and $m$ remain same as described above.

In the desorption study, $25 \mathrm{~mL}$ of $0.1 \mathrm{~mol} / \mathrm{L} \mathrm{NaOH}$ solution was used to desorb RR239 from the chitosan 8B flakes. The adsorbent was contacted with 25 $\mathrm{mL}$ of $100 \mu \mathrm{mol} / \mathrm{L}$ RR239 solution for $120 \mathrm{~min}$, filtered and the adsorbent was 
dried at room temperature $\left(30^{\circ} \mathrm{C}\right)$ overnight. The dye loaded-adsorbent was transferred into $25 \mathrm{~mL}$ desorbing solution and the mixture was stirred for 90 min. The amount of adsorption was determined in the same way as described above. All data presented in this paper are the mean of double measurements.

\section{Results and Discussion}

\subsection{Spectral Studies}

The chitosan 8B-RR239 complex was formulated by combining chitosan $8 \mathrm{~B}$ flakes with a solution of $\mathrm{RR} 239$ at $\mathrm{pH} 4$. The dye adsorption onto chitosan $8 \mathrm{~B}$ flakes was confirmed by diffuse reflectance electronic absorption spectra. In Figure 2, the absorption maxima of chitosan 8B-RR239 complex were observed at around 298 and $540 \mathrm{~nm}$ (Figure 2(c)), whereas free chitosan 8B flakes exhibited two absorption peaks at 220 and $300 \mathrm{~nm}$ (Figure 2(a)), respectively. RR239 dye revealed absorption peaks at 292 and $558 \mathrm{~nm}$ (Figure 2(b)), respectively. Hence the blue shift $18 \mathrm{~nm}$ of the absorption peak at $540 \mathrm{~nm}$, and the red shift 6 $\mathrm{nm}$ of the absorption peak at $298 \mathrm{~nm}$ must be attributed the adsorption of RR239 onto chitosan 8B flakes. However, the absorption maximum of free RR239 was found in the visible region at $541 \mathrm{~nm}$ in aqueous solution $(\mathrm{pH} 4$ 10).

\subsection{Adsorption Kinetics}

\subsubsection{Effect of $\mathrm{pH}$ on Adsorption Kinetics}

The surface charge of adsorbents and the configuration of dye molecules are significantly affected by solution $\mathrm{pH}$ [6]. Therefore, the $\mathrm{pH}$ of aqueous solution is a critical issue for the period of dye adsorption process. At present study, the effect of $\mathrm{pH}$ on the RR239 dye adsorption capacities of chitosan $8 \mathrm{~B}$ was conducted at varying $\mathrm{pH}(\mathrm{pH} 4-10)$ with $100 \mu \mathrm{mol} / \mathrm{L}$ fixed initial dye concentrations and adsorbent dosage $0.05 \mathrm{~g}$ for $120 \mathrm{~min}$. As can be seen from Figure 3, the adsorption of RR239 dye onto chitosan $8 \mathrm{~B}$ is intimately dependent on initial $\mathrm{pH}$ of aqueous solution. It is noticed that the dye adsorption rate was fast for initial $10 \mathrm{~min}$ and subsequently it progressed at a slower rate and lastly reached equilibrium within $\sim 60 \mathrm{~min}$. However, data were received for $120 \mathrm{~min}$ to confirm overall equilibrium. The initial rate of dye adsorption, $h(\mu \mathrm{mol} / \mathrm{g} \mathrm{min})$, decreased significantly with increasing solution $\mathrm{pH}$ (Table 1). After $120 \mathrm{~min}$ of sorption, the extent of equilibrium dye adsorption $\left(q_{e}\right)$ was observed to be $49.70 \mu \mathrm{mol} / \mathrm{g}$ at $\mathrm{pH} 4$ and $19.20 \mu \mathrm{mol} / \mathrm{g}$ at $\mathrm{pH} 10$ (Table 1), respectively. These results can be rationalized based on the changes in surface charges of adsorbent and the structure of dye ions with changing the $\mathrm{pH}$ of aqueous solution. The $\mathrm{pH}_{\mathrm{zpc}}$ of chitosan is 6.3. It assumes that the $99 \%$ of chitosan is protonated at $\mathrm{pH} 4.3$ [26]. Hence the positively charged exteriors of chitosan $8 \mathrm{~B}$ particles are magnificently adsorbed negatively charged dye anions in aqueous at $\mathrm{pH} 4$. On the other hand, the surfaces of chitosan $8 \mathrm{~B}$ particles turn into negative charges with rising the solution $\mathrm{pH}$, causing in repulsive forces between adsorbent and anionic dye adsorbate [26], 
which ultimately causes in a smaller adsorption. The suitable solution $\mathrm{pH}$ was found to be 4 within the examined solution $\mathrm{pH} 4-10$. Similar results were also observed in the adsorption of tartazine onto agricultural by-product [19] and reactive black 5 (RB5) onto chitosan [27] in aqueous solutions.

Table 1. Comparison of experimental and calculated $q_{\mathrm{e}}$ values, and kinetic parameters obtained from various kinetic models applied for the batch adsorption of RR239 dye onto chitosan $8 \mathrm{~B}$ in aqueous solution.

\begin{tabular}{|c|c|c|c|c|c|c|c|c|c|c|c|}
\hline \multirow[b]{2}{*}{ Parameters } & \multirow[b]{2}{*}{$\begin{array}{c}q_{e(\exp )} \\
(\mu \mathrm{mol} / \mathrm{g})\end{array}$} & \multicolumn{3}{|c|}{ Pseudo first-order model } & \multicolumn{4}{|c|}{ Pseudo second-order model } & \multicolumn{3}{|c|}{ Elovich model } \\
\hline & & $\begin{array}{c}k_{1} \\
(1 / \min )\end{array}$ & $\begin{array}{c}q_{e(c a)} \\
(\mu \mathrm{mol} / \mathrm{g})\end{array}$ & $R^{2}$ & $\begin{array}{l}k_{2}(\mathrm{~g} / \mu \mathrm{mol} \\
\mathrm{min})\end{array}$ & $\begin{array}{c}q_{e(c a)} \\
(\mu \mathrm{mol} / \mathrm{g})\end{array}$ & $\begin{array}{c}h(\mu \mathrm{mol} / \mathrm{g} \\
\min )\end{array}$ & $R^{2}$ & $\begin{array}{c}\alpha(\mu \mathrm{mol} / \mathrm{g} \\
\min )\end{array}$ & $\beta(\mathrm{g} / \mu \mathrm{mol})$ & $R^{2}$ \\
\hline \multicolumn{12}{|c|}{$\mathrm{pH}$} \\
\hline 4 & 49.70 & 0.0578 & 15.99 & 0.946 & 0.0114 & 50.51 & 29.07 & 0.999 & 946.87 & 0.1890 & 0.953 \\
\hline 5 & 43.33 & 0.0366 & 23.78 & 0.971 & 0.0043 & 44.64 & 8.67 & 0.999 & 49.86 & 0.1531 & 0.981 \\
\hline 6 & 41.13 & 0.0389 & 26.41 & 0.995 & 0.0036 & 42.92 & 6.68 & 0.999 & 33.62 & 0.1538 & 0.967 \\
\hline 7 & 34.13 & 0.0493 & 27.09 & 0.939 & 0.0041 & 35.71 & 5.19 & 0.999 & 29.01 & 0.1890 & 0.986 \\
\hline 8 & 33.27 & 0.0379 & 23.21 & 0.989 & 0.0035 & 35.21 & 4.34 & 0.999 & 16.25 & 0.1719 & 0.953 \\
\hline 9 & 30.10 & 0.0417 & 20.41 & 0.991 & 0.0045 & 31.75 & 4.49 & 0.999 & 23.07 & 0.2089 & 0.945 \\
\hline 10 & 19.20 & 0.0387 & 15.59 & 0.995 & 0.0046 & 20.70 & 1.96 & 0.999 & 5.99 & 0.2721 & 0.983 \\
\hline \multicolumn{12}{|c|}{$\begin{array}{l}{[\mathrm{RR} 239]} \\
(\mu \mathrm{mol} / \mathrm{L})\end{array}$} \\
\hline 30 & 14.57 & 0.0603 & 1.23 & 0.676 & 0.1941 & 14.62 & 41.49 & 1.000 & $3.40 \times 10^{6}$ & 1.3187 & 0.732 \\
\hline 50 & 25.03 & 0.0739 & 2.30 & 0.730 & 0.1148 & 25.13 & 72.46 & 1.000 & $2.29 \times 10^{6}$ & 0.7278 & 0.762 \\
\hline 100 & 49.33 & 0.0645 & 18.53 & 0.954 & 0.0108 & 50.25 & 27.39 & 1.000 & $1.35 \times 10^{3}$ & 0.1998 & 0.963 \\
\hline 150 & 59.77 & 0.0479 & 24.61 & 0.993 & 0.0062 & 60.98 & 23.09 & 0.999 & $1.17 \times 10^{3}$ & 0.1633 & 0.979 \\
\hline 200 & 71.67 & 0.0419 & 33.16 & 0.995 & 0.0039 & 72.99 & 20.79 & 0.999 & $6.17 \times 10^{2}$ & 0.1259 & 0974 \\
\hline \multicolumn{12}{|c|}{$\begin{array}{l}\text { Ionic strength } \\
(\mathrm{mol} / \mathrm{L})\end{array}$} \\
\hline 0.01 & 49.07 & 0.0606 & 10.74 & 0.929 & 0.0195 & 49.50 & 47.85 & 1.000 & $2.38 \times 10^{4}$ & 0.2628 & 0.934 \\
\hline 0.02 & 48.93 & 0.0672 & 13.67 & 0.976 & 0.0171 & 49.50 & 42.02 & 1.000 & $1.08 \times 10^{4}$ & 0.2463 & 0.943 \\
\hline 0.03 & 48.80 & 0.0539 & 12.48 & 0.946 & 0.0154 & 49.26 & 37.31 & 1.000 & $9.08 \times 10^{3}$ & 0.2445 & 0.953 \\
\hline 0.04 & 48.67 & 0.0534 & 12.71 & 0.953 & 0.0150 & 49.26 & 36.49 & 1.000 & $8.29 \times 10^{3}$ & 0.2433 & 0.954 \\
\hline \multicolumn{12}{|c|}{$\begin{array}{c}\text { Temperatures } \\
\left({ }^{\circ} \mathrm{C}\right)\end{array}$} \\
\hline 30 & 48.97 & 0.0458 & 20.31 & 0.939 & 0.0075 & 49.75 & 18.45 & 1.000 & $3.52 \times 10^{2}$ & 0.1743 & 0.972 \\
\hline 35 & 49.47 & 0.0610 & 20.51 & 0.972 & 0.0095 & 50.51 & 24.21 & 1.000 & $5.04 \times 10^{2}$ & 0.1764 & 0.957 \\
\hline 40 & 49.50 & 0.0534 & 18.20 & 0.974 & 0.0097 & 50.25 & 24.57 & 1.000 & $2.44 \times 10^{3}$ & 0.2159 & 0.979 \\
\hline 45 & 49.53 & 0.0619 & 17.03 & 0.941 & 0.0120 & 50.25 & 30.30 & 1.000 & $1.68 \times 10^{3}$ & 0.2032 & 0.956 \\
\hline
\end{tabular}




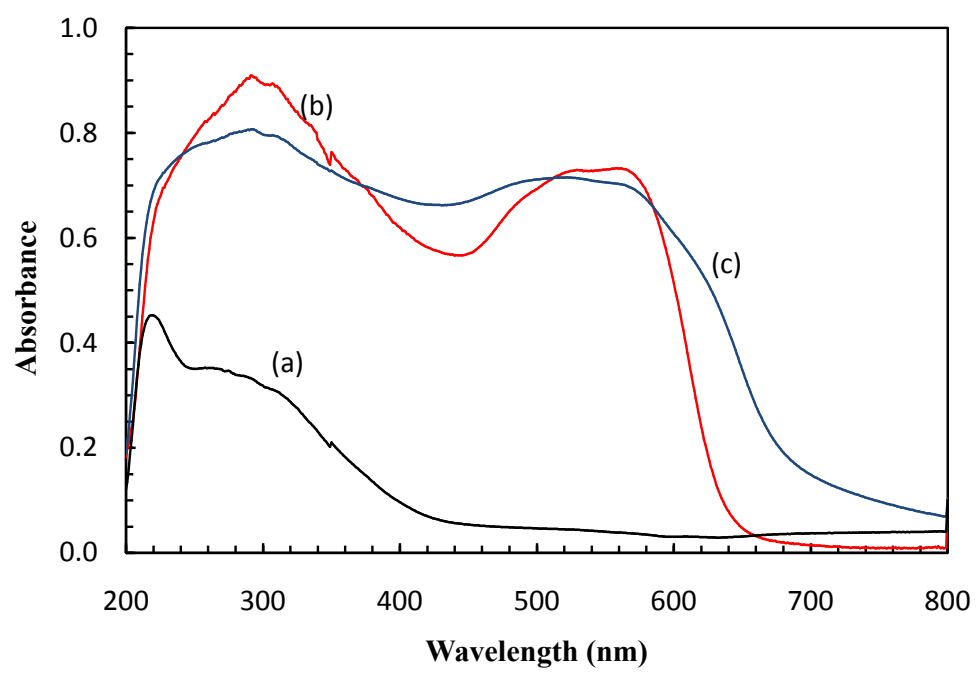

Figure 2. Diffuse reflectance electronic absorption spectra of (a) chitosan 8B flakes, (b) RR239, and (c) chitosan 8B-RR239 complex in KBr.

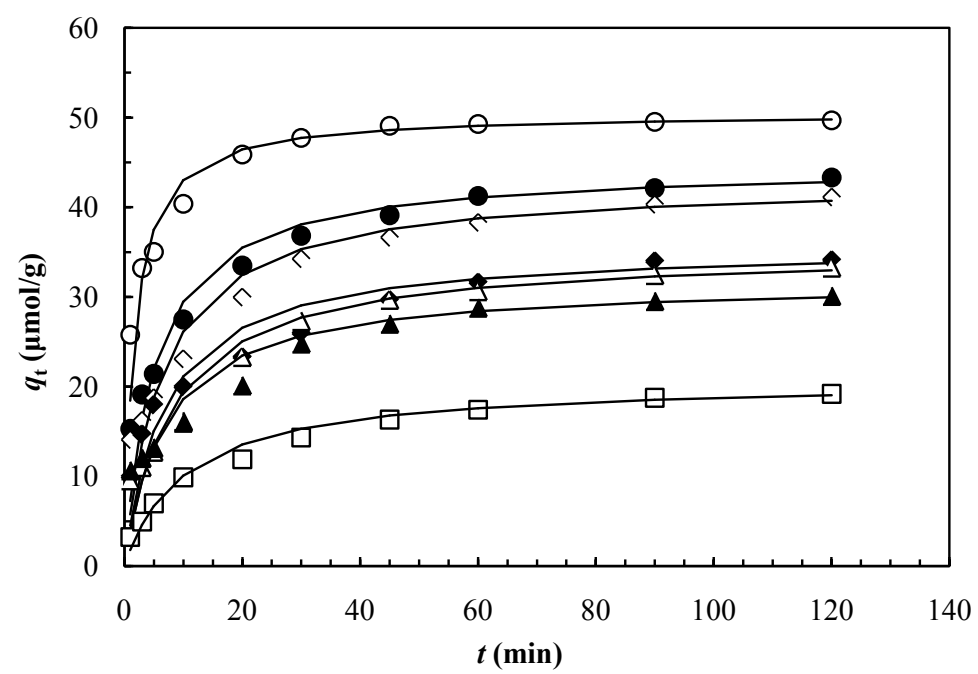

Figure 3. The effects of solution pHs on the adsorption kinetics of RR239 onto chitosan $8 \mathrm{~B}$ in aqueous solution ([RR239] $]_{0}$ dye: $100 \mu \mathrm{mol} / \mathrm{L}$; solution volume: $25 \mathrm{~mL}$; chitosan $8 \mathrm{~B}$ : $0.05 \mathrm{~g}$; temperature: $30^{\circ} \mathrm{C} \pm 0.2^{\circ} \mathrm{C}$; solution

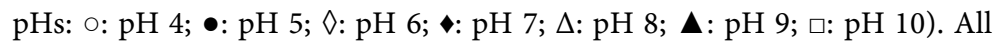
solid lines are numerically generated by using pseudo second-order adsorption kinetic Equation (4) and the values of $q_{e(c a)}$ and $k_{2}$ listed in Table 1.

\subsubsection{Effect of Initial Dye Concentration on Adsorption Kinetics}

The initial concentration supplies a significant pouring strength to overcome all mass transfer resistance of the dye between the aqueous and solid phases [21]. In this work, the influences of initial concentration of dye solutions on adsorption were studied in aqueous solution $(\mathrm{pH} 4)$ at $30^{\circ} \mathrm{C}$ for $120 \mathrm{~min}$ and the amount of chitosan $8 \mathrm{~B}$ was $0.05 \mathrm{~g}$. Remarkably, the amount of equilibrium RR239 dye adsorption, $q_{e}(\mu \mathrm{mol} / \mathrm{g})$, increases (Figure 4$)$, but the initial rate of RR239 dye adsorption, $h(\mu \mathrm{mol} / \mathrm{g} \mathrm{min})$, reduces with increasing initial dye concentration (Table 1), indicating that the RR239 dye adsorption onto chitosan $8 \mathrm{~B}$ is strongly 
concentration dependent. As can be seen from Figure 4, when the initial dye concentration increases from 30 to $200 \mu \mathrm{mol} / \mathrm{L}$, the extent of dye sorption capacities of chitosan $8 \mathrm{~B}$ increase from 14.57 to $71.67 \mu \mathrm{mol} / \mathrm{g}$. These results are in accordance with obtained findings by other researchers [21] [22].

\subsubsection{Effect of Ionic Strength on Adsorption Kinetics}

The solution ionic strength is an essential issue that influences both electrostatic and non-electrostatic interactions between dyes and adsorbent surfaces. The effect of ionic strength on the adsorption kinetics of RR239 onto chitosan 8B in aqueous solution $(\mathrm{pH} 4)$ was successively inspected by the adding various amounts of $\mathrm{Na}_{2} \mathrm{SO}_{4}$ salt to the $100 \mu \mathrm{mol} / \mathrm{L}$ dye solution at $30^{\circ} \mathrm{C}$. Results presented in Figure 5 obviously showed a decrease in both the initial dye adsorption rate, $h(\mu \mathrm{mol} / \mathrm{g} \mathrm{min})$, and the extent of dye adsorption, $q_{e}(\mu \mathrm{mol} / \mathrm{g})$, with increasing solution ionic strengths (Table 1). The results indicate that RR239 dye anions and $\mathrm{SO}_{4}^{2-}$ (from $\mathrm{Na}_{2} \mathrm{SO}_{4}$ ) are competing for the active sorption sites, which is good agreement with previous reports [20] [26]. This also confirms the electrostatic interactions between adsorbent and dye molecules.

\subsubsection{Effect of Temperature on Adsorption Kinetics}

The kinetics of RR239 dye adsorption onto chitosan $8 \mathrm{~B}$ was investigated in aqueous solution $(\mathrm{pH} 4)$ at four different temperatures, $30^{\circ} \mathrm{C}, 35^{\circ} \mathrm{C}, 40^{\circ} \mathrm{C}$ and $45^{\circ} \mathrm{C}$ and the results are depicted in Figure 6 where the initial concentration of dye solution was $100 \mu \mathrm{mol} / \mathrm{L}$. These results indicate that the initial rate of dye adsorption, $h(\mu \mathrm{mol} / \mathrm{g} \mathrm{min})$, and the amount of equilibrium dye adsorption, $q_{e}$ $(\mu \mathrm{mol} / \mathrm{g})$, increased with increasing the solution temperature $\left({ }^{\circ} \mathrm{C}\right)$. Therefore,

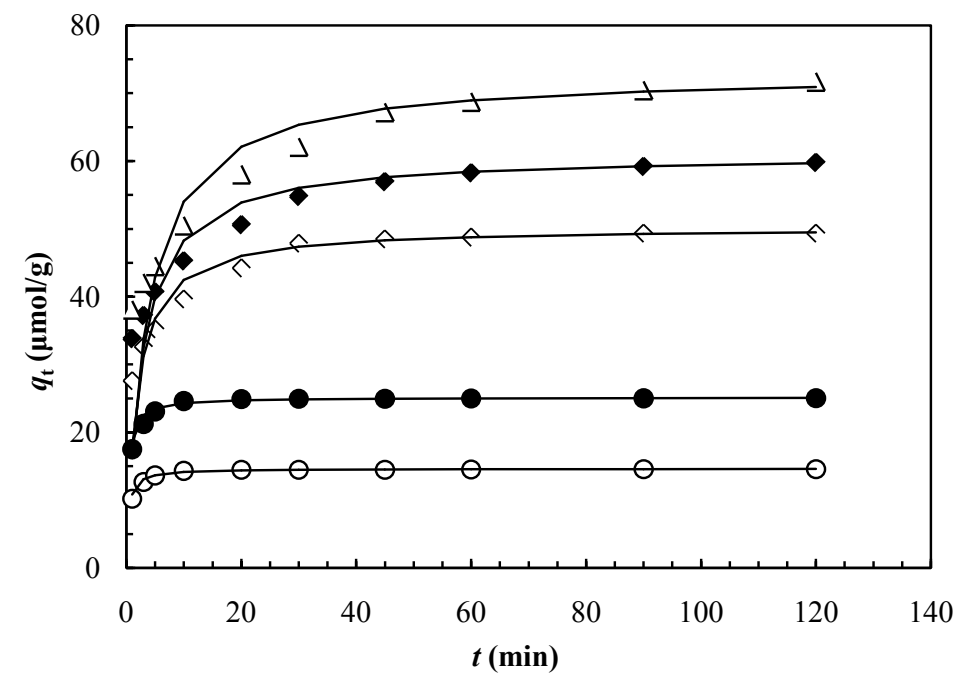

Figure 4. The effects of initial dye concentration on the adsorption kinetics of RR239 onto chitosan $8 \mathrm{~B}$ in aqueous solution ( $\mathrm{pH} 4$ ) (solution volume: 25 $\mathrm{mL}$; chitosan 8B: 0.05 g; temperature: $30^{\circ} \mathrm{C} \pm 0.2^{\circ} \mathrm{C}$; [RR239] $]_{0}$ : : $30 \mu \mathrm{mol} / \mathrm{L}$;

•: $50 \mu \mathrm{mol} / \mathrm{L} ; \diamond: 100 \mu \mathrm{mol} / \mathrm{L} ; \diamond: 150 \mu \mathrm{mol} / \mathrm{L} ; \Delta: 200 \mu \mathrm{mol} / \mathrm{L})$. All solid lines are numerically generated by using pseudo second-order adsorption kinetic Equation (4) and the values of $q_{e(c a)}$ and $k_{2}$ listed in Table 1. 


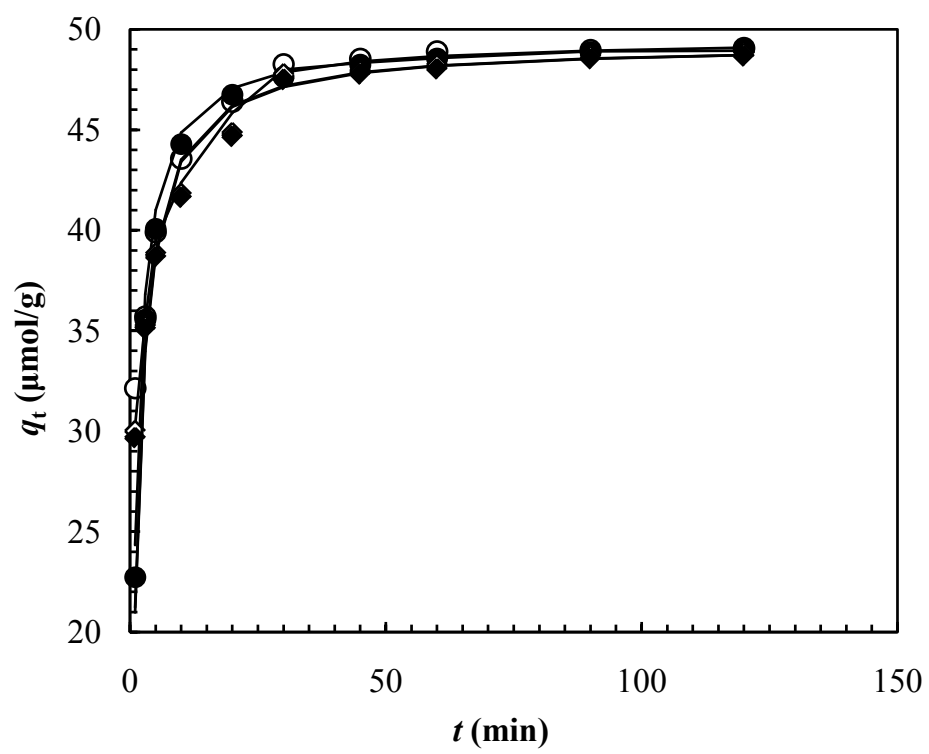

Figure 5. Adsorption kinetics of RR239 dye onto chitosan $8 \mathrm{~B}$ in aqueous solution at various ionic strengths ([RR239 $]_{0}: 100 \mu \mathrm{mol} / \mathrm{L}$; solution volume: $25 \mathrm{~mL}$; chitosan $8 \mathrm{~B}: 0.05$ g; temperature: $30^{\circ} \mathrm{C} \pm 0.2^{\circ} \mathrm{C}$; ionic strength: $\odot: 0.01 \mathrm{~mol} / \mathrm{L} ; \bullet: 0.02 \mathrm{~mol} / \mathrm{L} ; \diamond: 0.03 \mathrm{~mol} / \mathrm{L}$; ४ $0.04 \mathrm{~mol} / \mathrm{L}$ ). All solid lines are numerically generated by using pseudo second-order adsorption kinetic Equation (4) and the values of $q_{\mathrm{e}(\mathrm{cal})}$ and $k_{2}$ listed in Table 1.

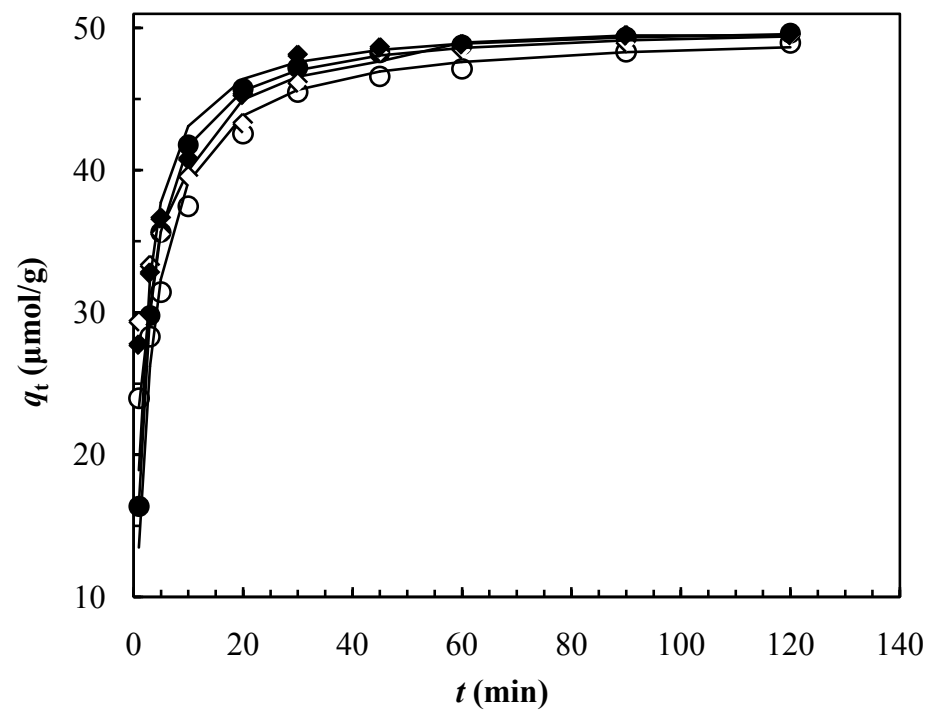

Figure 6. Adsorption kinetics of RR239 onto chitosan $8 \mathrm{~B}$ in aqueous solution at various temperatures ([RR239] $]_{0}: 100 \mu \mathrm{mol} / \mathrm{L}$; solution volume: $25 \mathrm{~mL}$; chitosan 8B: 0.05 g; temperature: $\circ: 30^{\circ} \mathrm{C}$; $\bullet: 35^{\circ} \mathrm{C}$; $\diamond: 40^{\circ} \mathrm{C}$; $45^{\circ} \mathrm{C}$ ). All solid lines are numerically generated by using pseudo second-order adsorption kinetic Equation (4) and the values of $q_{e(c a)}$ and $k_{2}$ listed in Table 1.

the RR239 dye molecules interact more efficiently with functional groups of chitosan $8 \mathrm{~B}$ at higher temperatures because the mobility of the dye molecules increased with rising solution temperature. This is expected that rising of the solution temperature may generate a swelling effect within the internal structure of chitosan 8 B [30]. Similar results were also observed in adsorption of RY145 and 
RB5 onto chitosan in aqueous solutions, respectively [26] [27].

\subsection{Modeling of Adsorption Kinetics}

The adsorption kinetics illustrates the dye uptake rate onto the adsorbent in adsorption reaction. This is an essential feature in expressing the efficacy of adsorption. Various kinetic models have been utilized to investigate the dye adsorption mechanisms in aqueous solutions. Here, pseudo first- [31], second-order [32], Elovich [33], and intraparticle diffusion [34] kinetic models were employed to calculate the adsorption kinetic data obtained from batch experiments. The pseudo first-order adsorption kinetics is usually stated by Equation (3):

$$
\log \left(q_{e}-q_{t}\right)=\log q_{e}-\frac{k_{1}}{2.0303} t
$$

where $k_{1}(1 / \mathrm{min})$ is the pseudo first-order sorption rate constant estimated from the slope of a plot $\log \left(q_{e}-q_{t}\right)$ versus $t$.

The pseudo second-order kinetic model is expressed as:

$$
q_{t}=\frac{k_{2} q_{e}^{2} t}{1+k_{2} q_{e} t}
$$

where $k_{2}(\mathrm{~g} / \mu \mathrm{mol} \mathrm{min})$ is the pseudo second-order adsorption rate constant calculated from a linearized form of this equation, represented by Equation (5):

$$
\frac{t}{q_{t}}=\frac{1}{k_{2} q_{e}^{2}}+\frac{1}{q_{e}} t
$$

The plot of $t / q_{t}$ versus $t$ would exhibit a straight line if pseudo second-order kinetics is applicable. The values of $k_{2}$ and $q_{e}$ were obtained from intercept and slope of the straight line. The initial rate of adsorption, $h$ ( $\mu \mathrm{mol} / \mathrm{g} \mathrm{min})$, is able to know by Equation (6):

$$
h=k_{2} q_{e}^{2}
$$

The Elovich model is generally expressed as:

$$
q_{t}=\frac{1}{\beta} \ln (\alpha \beta)+\frac{1}{\beta} \ln t
$$

where $\alpha(\mu \mathrm{mol} / \mathrm{g} \mathrm{min})$ is an initial rate of dye adsorption and $\beta(\mathrm{g} / \mu \mathrm{mol})$ is associated to the degree of surface coverage and the activation energy for chemisorption. The Elovich coefficients can be estimated from the plot of $q_{t}$ versus $\ln t$.

The values of correlation coefficients $\left(R^{2}\right)$ and kinetic parameters obtained from various applied kinetic models are presented in Table 1 . The values of $R^{2}$ obtained from pseudo first-order $(\leq 0.995)$ and Elovich $(\leq 0.986)$ kinetic models are insignificant compare to the values of $R^{2}(\geq 0.999)$ found in the cases of pseudo second-order kinetic model. Moreover, the calculated $q_{e(c a)}$ values from pseudo second-order kinetic model and the experimental $q_{e(\exp )}$ values are comparable (Table 1) suggesting a promising condition for pseudo second-order adsorption kinetics. Similar results were also observed in the adsorption of 
RY145 and RB5 onto chitosan, respectively [26] [27].

The intraparticle diffusion model equation can be written as:

Intraparticle diffusion model: $q_{t}=k_{i d} t^{0.5}+I$

where $k_{i d}\left(\mu \mathrm{mol} / \mathrm{g} \min ^{0.5}\right)$ is the intraparticle diffusion rate constant and $I$ $(\mu \mathrm{mol} / \mathrm{g})$ is the intercept. The typical intraparticle diffusion plots for the effect of initial dye concentration on the adsorption of RR239 onto chitosan 8B were shown in Figure 7. From this figure, it was observed that there were two linear portions. The intraparticle diffusion constants, $k_{i d 1}\left(\mu \mathrm{mol} / \mathrm{g} \mathrm{min}^{0.5}\right)$ and $k_{i d 2}$ $\left(\mu \mathrm{mol} / \mathrm{g} \min ^{0.5}\right)$, are calculated from the slope of the corresponding linear regions of Figure 7. The values of $k_{i d 1}\left(\mu \mathrm{mol} / \mathrm{g} \mathrm{min}^{0.5}\right)$ and $k_{i d 2}\left(\mu \mathrm{mol} / \mathrm{g} \mathrm{min}^{0.5}\right)$ express diffusion rates of the different stages in the adsorption (Table 2).

The changes of $k_{i d 1}\left(\mu \mathrm{mol} / \mathrm{g} \mathrm{min}^{0.5}\right)$ and $k_{i d 2}\left(\mu \mathrm{mol} / \mathrm{g} \mathrm{min}^{0.5}\right)$ represent to the adsorption levels of the exterior and interior surfaces of adsorbent [35]. The dye adsorption rate was very fast at the early stage because the RR239 was adsorbed by the exterior surface of chitosan $8 \mathrm{~B}$ particle. When exterior surface of chitosan $8 \mathrm{~b}$ was saturated then RR239 dye molecules entered into chitosan $8 \mathrm{~B}$ particles and were adsorbed by the interior surface of the chitosan particles. The diffusion rate became slow. From Figure 7, it is also be noticed that none of the straight lines at any concentration of RR239 solution passes through the origin, which suggests that the dye adsorption mechanism was complex and both surface adsorption as well as intraparticle diffusion contributed to the actual sorption process. Similar results were also observed in the adsorption of RY145 onto chitosan in aqueous solution [26].

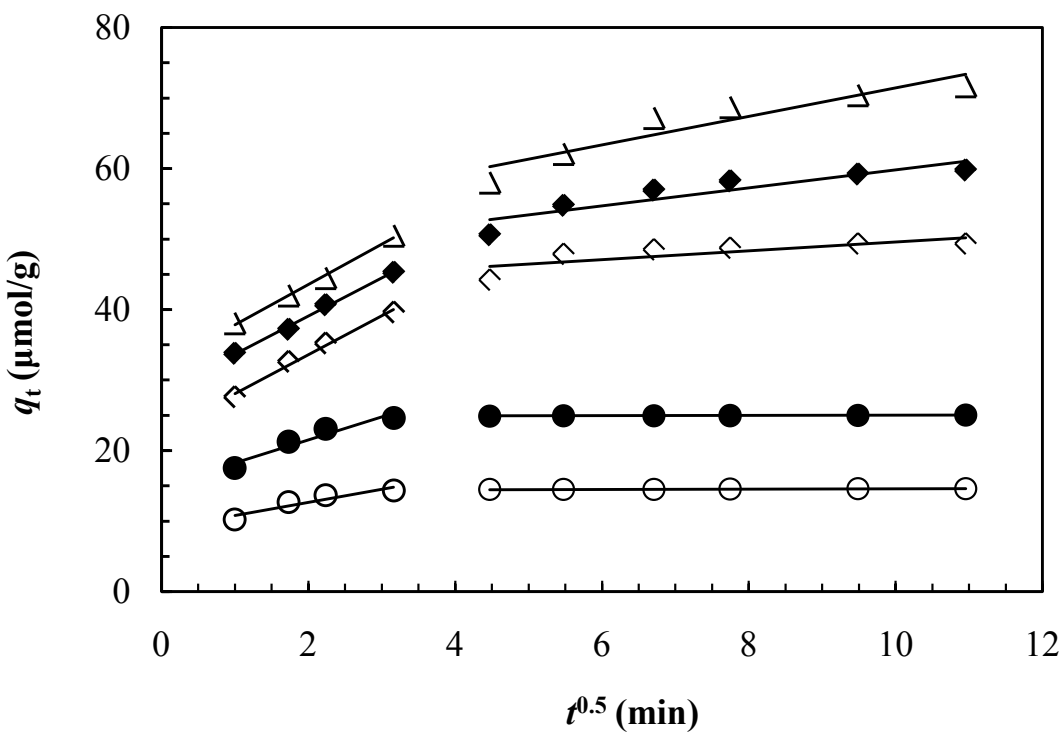

Figure 7. Typical intraparticle diffusion model plots for the adsorption of RR239 dye on Chitosan $8 \mathrm{~B}$ at various initial concentrations (solution volume: $25 \mathrm{~mL}$; chitosan 8B: 0.05 g; temperature: $30^{\circ} \mathrm{C} \pm 0.2^{\circ} \mathrm{C}$; initial concentrations of RR239: $\circ$ : $30 \mu \mathrm{mol} / \mathrm{L} ; \bullet: 50 \mu \mathrm{mol} / \mathrm{L} ; \diamond: 100 \mu \mathrm{mol} / \mathrm{L} ; \diamond: 150 \mu \mathrm{mol} / \mathrm{L} ; \Delta: 200 \mu \mathrm{mol} / \mathrm{L})$. The values of $k_{i d 1}\left(\mu \mathrm{mol} / \mathrm{g} \mathrm{min}^{0.5}\right)$ and $k_{i d 2}\left(\mu \mathrm{mol} / \mathrm{g} \mathrm{min}^{0.5}\right)$ are listed in Table 2. 
Table 2. Diffusion rate parameters $\left(k_{i d 1}\right.$ and $k_{i d 2}$ ) for the adsorption of RR239 onto chitosan $8 \mathrm{~B}$ in aqueous solution at various conditions.

\begin{tabular}{|c|c|c|c|c|c|c|}
\hline Parameters & $\begin{array}{c}k_{i d 1} \\
\left(\mu \mathrm{mol} / \mathrm{g} \min ^{0.5}\right)\end{array}$ & $\begin{array}{c}I_{1} \\
(\mu \mathrm{mol} / \mathrm{g})\end{array}$ & $R^{2}$ & $\begin{array}{c}k_{i d 2} \\
\left(\mu \mathrm{mol} / \mathrm{g} \min ^{0.5}\right)\end{array}$ & $\begin{array}{c}I_{1} \\
(\mu \mathrm{mol} / \mathrm{g})\end{array}$ & $R^{2}$ \\
\hline \multicolumn{7}{|c|}{$\mathrm{pH}$} \\
\hline 4 & 5.544 & 22.100 & 0.967 & 0.306 & 46.599 & 0.728 \\
\hline 5 & 5.333 & 9.932 & 0.996 & 1.137 & 31.363 & 0.924 \\
\hline 6 & 4.667 & 8.656 & 0.992 & 1.251 & 28.031 & 0.958 \\
\hline 7 & 3.656 & 7.972 & 0.928 & 1.468 & 19.223 & 0.888 \\
\hline 8 & 4.009 & 4.440 & 0.97 & 1.058 & 22.120 & 0.957 \\
\hline 9 & 2.776 & 7.396 & 0.989 & 0.927 & 20.559 & 0.878 \\
\hline 10 & 2.592 & 0.867 & 0.973 & 0.869 & 10.193 & 0.928 \\
\hline \multicolumn{7}{|c|}{ [RR239] $(\mu \mathrm{mol} / \mathrm{L})$} \\
\hline 30 & 3.535 & 27.157 & 0.869 & 0.124 & 37.630 & 0.857 \\
\hline 50 & 8.005 & 27.232 & 0.828 & 0.169 & 50.767 & 0.790 \\
\hline 100 & 8.405 & 36.348 & 0.794 & 0.324 & 61.113 & 0.788 \\
\hline 150 & 12.422 & 29.015 & 0.965 & 0.498 & 71.02 & 0.699 \\
\hline 200 & 13.042 & 33.453 & 0.994 & 2.399 & 77.333 & 0.807 \\
\hline \multicolumn{7}{|c|}{ Ionic strength $(\mathrm{mol} / \mathrm{L})$} \\
\hline 0.01 & 4.169 & 29.033 & 0.945 & 0.143 & 47.591 & 0.865 \\
\hline 0.02 & 4.339 & 27.757 & 0.931 & 0.175 & 47.138 & 0.935 \\
\hline 0.03 & 4.130 & 27.730 & 0.925 & 0.203 & 46.638 & 0.976 \\
\hline 0.04 & 4.162 & 27.457 & 0.922 & 0.225 & 46.282 & 0.979 \\
\hline \multicolumn{7}{|c|}{ Temperatures $\left({ }^{\circ} \mathrm{C}\right)$} \\
\hline 30 & 5.449 & 19.013 & 0.989 & 0.628 & 42.233 & 0.987 \\
\hline 35 & 6.066 & 19.591 & 0.939 & 0.534 & 44.113 & 0.836 \\
\hline 40 & 3.991 & 26.162 & 0.983 & 0.519 & 44.106 & 0.787 \\
\hline 45 & 4.999 & 24.046 & 0.969 & 0.267 & 46.763 & 0.947 \\
\hline
\end{tabular}

\subsection{Activation Parameters}

The values of $k_{2}$ at various temperatures recorded in Table 1 were utilized to determine the activation energy for the adsorption of RR239 dye onto chitosan $8 \mathrm{~B}$ in aqueous solution. According to Arrhenius equation, the rate constant $\left(k_{2}\right)$, temperature $(T)$ and activation energy $\left(E_{a}\right)$ can be expressed by Equation (9):

$$
\ln k_{2}=-\frac{E_{a}}{R T}+\text { constant }
$$

where $R(8.314 \mathrm{~J} / \mathrm{mol} K)$ is the gas constant. The value of $E_{a}$ was determined be $23.30 \mathrm{~kJ} / \mathrm{mol}$ from the slope of straight line obtained from $\ln k_{2}$ versus $1 / T$ plot $\left(R^{2}=0.928\right)$ in temperature range $30^{\circ} \mathrm{C}-45^{\circ} \mathrm{C}$. Literature survey showed that the values of $E_{a}$ were obtained to be $33.35 \mathrm{~kJ} / \mathrm{mol}$ for the reactive dye adsorption on 
carbon nanotubes [36], $19.72 \mathrm{~kJ} / \mathrm{mol}$ for the RY145 dye adsorption onto chitosan [26] and $33.96 \mathrm{~kJ} / \mathrm{mol}$ for the maxilon blue GRL dye adsorption onto sepiolite

[37]. It is well known that the extent of the activation energy produces evidence on whether the adsorption is mainly physical or chemical. Wu reported that the activation energy of $5-40 \mathrm{~kJ} / \mathrm{mol}$ is normally for physisorption process and a higher activation energy $(40-800 \mathrm{~kJ} / \mathrm{mol})$ is for chemisorption process [36]. The value of $E_{a}(23.30 \mathrm{~kJ} / \mathrm{mol})$ suggests that the present adsorption is a physisorption process.

The other thermodynamic activation parameters such as changes in entropy of activation $\left(\Delta S^{\ddagger}\right)$, changes in enthalpy of activation $\left(\Delta H^{\ddagger}\right)$, and changes in Gibbs free energy of activation $\left(\Delta G^{\ddagger}\right)$, are expressed by the following relations [26]:

$$
\begin{gathered}
\ln \left(\frac{k_{2}}{T}\right)=-\frac{\Delta H^{\ddagger}}{R T}+\ln \frac{k_{B}}{h_{P}}+\frac{\Delta S^{\ddagger}}{R} \\
\Delta G^{\ddagger}=\Delta H^{\ddagger}-T \Delta S^{\ddagger}
\end{gathered}
$$

where $k_{2}(\mathrm{~g} / \mathrm{mol} \mathrm{min}), R$ and $T$ are same as described before, $k_{B}$ is the Boltzman constant $\left(k_{B}=1.381 \times 10^{-23} \mathrm{~J} / \mathrm{K}\right)$ and $h_{P}$ is the Plank constant $\left(h_{P}=6.626 \times 10^{-34}\right.$ Js). The values of $\Delta H^{\ddagger}$ and $\Delta S^{\ddagger}$ were determined from the slope and y-intercept of the straight line obtained from the plot $\ln \left(k_{2} / T\right)$ versus $1 / T\left(R^{2}=0.911\right)$. The $\Delta H^{\ddagger}$ value was estimated to be $20.72 \mathrm{~kJ} / \mathrm{mol}$. The low value of $\Delta H^{\ddagger}$ shows that the interactions between RR239 and chitosan $8 \mathrm{~B}$ are weak. The value of $\Delta S^{*}$ was determined to be $-102.33 \mathrm{~J} / \mathrm{mol} \mathrm{K}$, which indicates that the RR239 anions at activated state and at the interface are always more organized than those in the bulk solution phase [38]. Similar results were also observed in the removal of malachite green from wastewater using activated carbon and activated slag [39]. The value of $T_{a v} \Delta S^{+}$was calculated to be $-31.77 \mathrm{~kJ} / \mathrm{mol}$ where $T_{a v}$ represents the average value of four temperatures used for adsorption studies. The value of $\Delta H^{*}$ was found to be smaller than that of $T_{a v} \Delta S^{\ddagger}\left(\Delta H^{\ddagger}<T_{a v} \Delta S^{\sharp}\right)$ which indicates that the impact of entropy is more significant than enthalpied in activation [38]. Moreover, the values of $\Delta G^{\ddagger}$ were found to be $51.72,52.23,52.75$ and 53.26 $\mathrm{kJ} / \mathrm{mol}$ at $30^{\circ} \mathrm{C}, 35^{\circ} \mathrm{C}, 40^{\circ} \mathrm{C}$ and $45^{\circ} \mathrm{C}$, respectively. The positive values of $\Delta G^{*}$ suggest the existence of an energy barrier in the adsorption process [26].

\subsection{Reuse of the Chitosan}

The typical phenomena of RR239 dye adsorption-desorption-adsorption onto chitosan 8B flakes in aqueous are shown in Figure 8. In adsorption step, the initial dye concentration was $100 \mu \mathrm{mol} / \mathrm{L}$ with a solution $\mathrm{pH} 4.0$ and a temperature $30^{\circ} \mathrm{C}$ whereas the release of RR239 from dye-loaded chitosan $8 \mathrm{~B}$ was carried out in $0.1 \mathrm{M} \mathrm{NaOH}$ solution at $\mathrm{pH} 12.5$ and temperature $30^{\circ} \mathrm{C}$. It is observed that the amount of equilibrium dye adsorption was $49.70 \mu \mathrm{mol} / \mathrm{g}$ in the first adsorption step which was persisted for $120 \mathrm{~min}$. The dye desorption rate was rapid for first 20 min and $85 \%$ of RR239 dye was released from dye-loaded chitosan within 35 
min. After 90 min of desorption, the liberated dye from RR239-loaded chitosan was $89 \%$. This may be due to the fact that in a basic solution, the positively charged amino groups of chitosan $8 \mathrm{~B}$ are deprotonated, and the electrostatic interaction between chitosan and dye molecules becomes much weaker [27]. Following the desorption step, the second adsorption step took place and it repeated the similar dynamical shape of the first adsorption step. It takes $120 \mathrm{~min}$ to adsorb the similar amount of dye RR239 as that of desorption, and the total amount of dye adsorption is the same as that of the first adsorption step. These results show that our chitosan flakes can be reused for further dye adsorption.

\subsection{Adsorption Isotherm}

The analysis of the adsorption isotherm data is important to know the nature of the interaction between adsorbate and the adsorbent used for the eliminating of organic pollutants. A plot of $q_{e}$ versus $C_{e}$ at various temperatures is presented in Figure 9. The values of $q_{e}$ increased with increasing solution temperature from $30^{\circ} \mathrm{C}$ to $45^{\circ} \mathrm{C}$ indicating that the present adsorption is an endothermic process.

The adsorption isotherm data were examined by using four isotherm models such as Ferundlich [40], Temkin [41], Dubinin-Radushkevich [42], and Langmuir [43]. Nonlinear and linear forms of all the applied models are presented as follows.

Freundlich model:

$$
\begin{aligned}
& \text { Nonlinear form } q_{e}=K_{F} C_{e}^{\frac{1}{n}} \\
& \text { Linear form } \ln q_{e}=\frac{1}{n} \ln C_{e}+\ln K_{F}
\end{aligned}
$$

Temkin model:

$$
\begin{aligned}
& \text { Nonlinear form } q_{e}=\frac{R T}{b} \ln \left(K_{T} C_{e}\right) \\
& \text { Linear form } q_{e}=\frac{R T}{b} \ln K_{T}+\frac{R T}{b} \ln C_{e}
\end{aligned}
$$

Dubinin-Radushkevich model:

$$
\begin{gathered}
\text { Nonlinear form } q_{e}=q_{D R} \exp \left(-K_{D R} \varepsilon^{2}\right) \\
\text { Linear form } \ln q_{e}=\ln q_{D R}-K_{D R} \varepsilon^{2}
\end{gathered}
$$

where $\varepsilon=R T \ln \left(1+\frac{1}{C_{e}}\right)$

Langmuir model:

$$
\begin{aligned}
& \text { Nonlinear form } q_{e}=\frac{K_{L} C_{e}}{1+a_{L} C_{e}} \\
& \text { Linear form } \frac{C_{e}}{q_{e}}=\frac{1}{K_{L}}+\frac{a_{L}}{K_{L}} C_{e}
\end{aligned}
$$

where $C_{e}(\mu \mathrm{mol} / \mathrm{L})$ is the equilibrium RR239 dye concentration in solution, $K_{F}$ 
$\left((\mu \mathrm{mol} / \mathrm{g})(\mu \mathrm{mol} / \mathrm{L})^{-1 / n}\right)$ and $n$ are Freundlich isotherm constants indicating the capacity and intensity of the adsorption, respectively. $K_{T}(\mu \mathrm{mol} / \mathrm{L})$ is the Temkin isotherm constant, $b(\mathrm{~J} / \mathrm{mol})$ is a constant related to heat of adsorption, $R(8.314$ $\mathrm{J} / \mathrm{mol} \mathrm{K}$ ) is an ideal gas constant and $T$ is the absolute temperature (K). The $q_{e}$ $(\mu \mathrm{mol} / \mathrm{g})$ is the amount of equilibrium RR239 dye adsorbed per unit weight of adsorbent, $q_{D R}$ is the maximum adsorption capacity, $\left.K\left(\mathrm{~mol}^{2} / \mathrm{kJ}\right)^{2}\right)$ is the activity coefficient useful in obtaining the mean sorption energy $E(\mathrm{~kJ} / \mathrm{mol})$ and $\varepsilon$ is the Polanyi potential. $K_{L}(\mathrm{~L} / \mathrm{g})$ and $a_{L}(\mathrm{~L} / \mu \mathrm{mol})$ are the characteristic constants of the Langmuir equation, and the ratio of $K_{L} / a_{L}$ gives the maximum dye adsorption capacity $q_{m}(\mu \mathrm{mol} / \mathrm{g})$ of chitosan $8 \mathrm{~B}$. The values of isotherm parameters are given in Table 3. In all cases, Langmuir isotherm has highest correlation coefficients $\left(R^{2}\right)$, which is considerably a better fit compared with Freundlich, Temkin and Dubinin-Radushkevich adsorption isotherms.

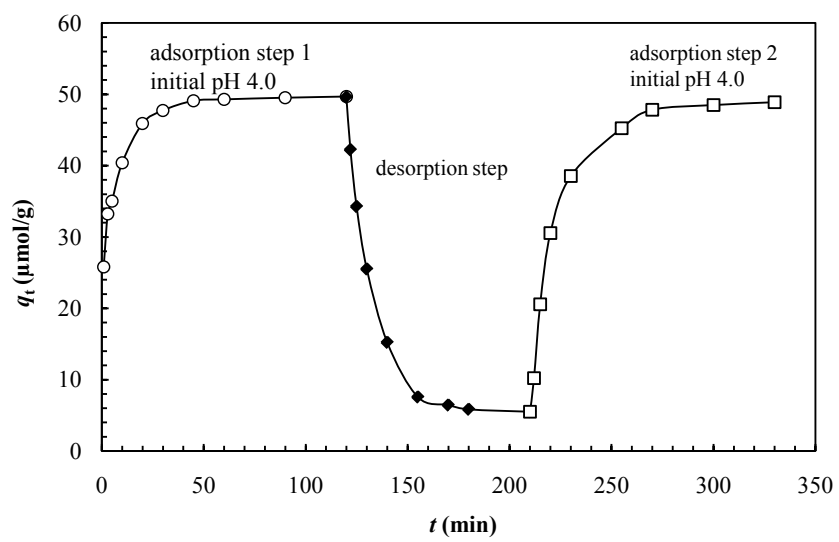

Figure 8. Adsorption and desorption kinetics of RR239 on chitosan $8 \mathrm{~B}$ in aqueous solution at $30^{\circ} \mathrm{C}$ and $100 \mu \mathrm{mol} / \mathrm{L}$ initial dye concentration with three steps: adsorption step 1 at initial $\mathrm{pH} 4.0$, desorption step at initial $\mathrm{pH} 12.5$, and adsorption step 2 at initial $\mathrm{pH} 4.0$.

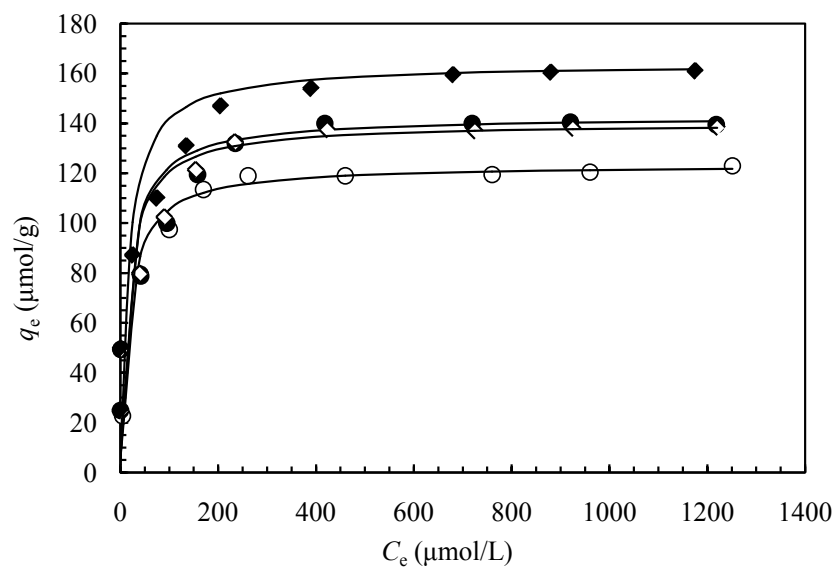

Figure 9. Adsorption isotherm of RR239 onto chitosan 8B in aqueous solution at various temperatures ([RR239] $]_{0}: 50-1500 \mu \mathrm{mol} / \mathrm{L}$; solution volume: $25 \mathrm{~mL}$; chitosan: 0.05 g; solution: $\mathrm{pH} 4$; temperatures: $\circ$ : $30^{\circ} \mathrm{C}$; $\bullet: 35^{\circ} \mathrm{C}$; $\diamond: 40^{\circ} \mathrm{C}$; $\bullet: 45^{\circ} \mathrm{C}$ ). All solid lines are numerically generated by using the Langmuir model in Equation (18) and the Langmuir isotherm constants listed in Table 3. 
Table 3. Freundlich, Temkin, Dubinin-Radushkevich and Langmuir isotherm constants at different temperatures and thermodynamic parameters for the adsorption of dye RR239 onto chitosan $8 \mathrm{~B}$ in aqueous solution at $\mathrm{pH} 4$.

\begin{tabular}{|c|c|c|c|c|}
\hline Parameters & \multicolumn{4}{|c|}{ Freundlich isotherm } \\
\hline$T\left({ }^{\circ} \mathrm{C}\right)$ & 30 & 35 & 40 & 45 \\
\hline$K_{F}\left((\mu \mathrm{mol} / \mathrm{g})(\mu \mathrm{mol} / \mathrm{L})^{-1 / \mathrm{n}}\right)$ & 36.885 & 38.425 & 38.502 & 49.824 \\
\hline$n$ & 5.266 & 4.933 & 4.955 & 5.485 \\
\hline$R^{2}$ & 0.900 & 0.940 & 0.919 & 0.967 \\
\hline Parameters & \multicolumn{4}{|c|}{ Temkin isotherm } \\
\hline$T\left({ }^{\circ} \mathrm{C}\right)$ & 30 & 35 & 40 & 45 \\
\hline$K_{T}(\mu \mathrm{mol} / \mathrm{L})$ & 24.487 & 14.702 & 14.919 & 64.777 \\
\hline$b(\mathrm{~J} / \mathrm{mol})$ & 201.741 & 171.848 & 175.616 & 182.991 \\
\hline$R^{2}$ & 0.963 & 0.957 & 0.957 & 0.965 \\
\hline Parameters & \multicolumn{4}{|c|}{ Dubinin-Radushkevich isotherm } \\
\hline$T\left({ }^{\circ} \mathrm{C}\right)$ & 30 & 35 & 40 & 45 \\
\hline$q_{D R}(\mu \mathrm{mol} / \mathrm{g})$ & 107.32 & 116.75 & 120.00 & 129.67 \\
\hline$K\left(\mathrm{~J}^{2} / \mathrm{mol}^{2}\right)$ & $2.00 \times 10^{-7}$ & $2.00 \times 10^{-7}$ & $2.00 \times 10^{-7}$ & $3.00 \times 10^{-7}$ \\
\hline$E(\mathrm{~kJ} / \mathrm{mol})$ & 1.58 & 1.58 & 1.58 & 4.08 \\
\hline$R^{2}$ & 0.899 & 0.825 & 0.895 & 0.816 \\
\hline Parameters & \multicolumn{4}{|c|}{ Langmuir isotherm } \\
\hline$T\left({ }^{\circ} \mathrm{C}\right)$ & 30 & 35 & 40 & 45 \\
\hline$K_{L}(\mathrm{~L} / \mathrm{g})$ & 7.148 & 8.496 & 8.496 & 10.225 \\
\hline$a_{L}(\mathrm{~L} / \mu \mathrm{mol})$ & 0.0579 & 0.0595 & 0.0603 & 0.0624 \\
\hline$q_{m}(\mu \mathrm{mol} / \mathrm{g})$ & 123.46 & 142.86 & 140.85 & 163.93 \\
\hline$R_{L}$ & 0.0113 & 0.0111 & 0.0109 & 0.0106 \\
\hline$R^{2}$ & 0.999 & 0.999 & 0.999 & 0.999 \\
\hline \multicolumn{5}{|l|}{ Thermodynamic parameters } \\
\hline$T\left({ }^{\circ} \mathrm{C}\right)$ & 30 & 35 & 40 & 45 \\
\hline$\Delta G(\mathrm{~kJ} / \mathrm{mol})$ & -27.63 & -28.15 & -28.64 & -29.19 \\
\hline$\Delta H(\mathrm{~kJ} / \mathrm{mol})$ & \multicolumn{4}{|c|}{3.80} \\
\hline$\Delta S(\mathrm{~J} / \mathrm{K} \mathrm{mol})$ & \multicolumn{4}{|c|}{103.72} \\
\hline$R^{2}$ & \multicolumn{4}{|c|}{0.977} \\
\hline
\end{tabular}

It is stated that the characteristics of the Langmuir isotherm can be expressed in terms of separation factor $\left(R_{L}\right)$ [44], which is expressed in Equation (20):

$$
R_{L}=\frac{1}{1+a_{L} C_{0}}
$$


where $a_{L}(\mathrm{~L} / \mu \mathrm{mol})$ is the Langmuir equilibrium constant and $C_{0}(\mu \mathrm{mol} / \mathrm{L})$ is the highest initial dye concentration. The shape of the isotherm can be interpreted as shown in Table 4 based on the value of $R_{L}$. The values of $R_{L}$ were found to be from 0 to 1 at $30^{\circ} \mathrm{C}, 35^{\circ} \mathrm{C}, 40^{\circ} \mathrm{C}$ and $45^{\circ} \mathrm{C}$, respectively, which indicates that the adsorption is favorable at all temperatures [26].

The applicability of the Langmuir model suggests homogeneous surfaces of the chitosan $8 \mathrm{~B}$ and monolayer coverage of RR239 dye onto the adsorbent. According to Langmuir, the maximum dye adsorption capacity of chitosan $8 \mathrm{~B}$ was found to be $123.46 \mu \mathrm{mol} / \mathrm{g}$ at $30^{\circ} \mathrm{C}$ and $163.93 \mu \mathrm{mol} / \mathrm{g}$ at $45^{\circ} \mathrm{C}$, respectively. This value is much higher than that of previously reported adsorbents as shown in Table 5 [45] [46] [47].

\subsection{Thermodynamics}

Thermodynamic parameters related to the adsorption process, i.e., Gibb's free energy change ( $\Delta G, \mathrm{~kJ} / \mathrm{mol})$, enthalpy change $(\Delta H, \mathrm{~kJ} / \mathrm{mol})$, and entropy change $(\Delta S, \mathrm{~J} / \mathrm{mol} \mathrm{K})$ are determined by using the values of Langmuir binding constant $\left(a_{L}, \mathrm{~L} / \mathrm{mol}\right)$ and the following equations:

$$
\begin{gathered}
\Delta G=-R T \ln a_{L} \\
\ln a_{L}=\frac{\Delta S}{R}-\frac{\Delta H}{R T}
\end{gathered}
$$

Table 4. The relation between the value of $R_{L}$ and type of adsorption.

\begin{tabular}{cc}
\hline Value of $R_{L}$ & Type of adsorption \\
\hline$R_{L}>1.0$ & Unfavorable \\
$R_{L}=1.0$ & Linear \\
$0<R_{L}<1.0$ & Favorable \\
$R_{L}=0$ & Irreversible \\
\hline
\end{tabular}

Table 5. The maximum adsorption capacity $\left(q_{m}\right)$ for RR239 of various adsorbents.

\begin{tabular}{ccc}
\hline Adsorbents & $q_{m}(\mu \mathrm{mol} / \mathrm{g})$ & Reference \\
\hline $\begin{array}{c}\text { 2,2'-(butane-1,4-diylbis(oxy))dibenzaldehyde cross-linked } \\
\text { magnetic chitosan nanoparticles }\end{array}$ & 176.01 & {$[17]$} \\
Chitosan 8B & 163.93 & This study \\
Hexamethylenediamine (HMDA)-modified zeolite & 25.14 & {$[45]$} \\
Formaldehyde treated carra sawdust & 13.29 & {$[16]$} \\
$\begin{array}{c}\text { Hexadecyltrimethylammonium bromide } \\
\text { (HTAB)-modified zeolite }\end{array}$ & 9.78 & {$[46]$} \\
Hexadecyltrimethylammonium bromide \\
(HTAB)-modified sepiolite
\end{tabular}


where $R(8.314 \mathrm{~J} / \mathrm{mol} \mathrm{K})$ is the universal gas constant and $T$ is the absolute temperature (K). $\Delta H$ and $\Delta S$ values can be calculated from the slope and $y$-intercept of the linear polt of $\ln a_{L}$ versus $1 / T\left(R^{2}=0.978\right)$. The thermodynamic results are presented in Table 3. Enthalpy changes $(\Delta H)$ indicate that the present adsorption followed endothermic processes. The positive values of $\Delta S$ confirm that there was increase in the randomness at the solid-liquid interface during the adsorption of RR239 onto chitosan $8 \mathrm{~B}$, which results from the higher translational entropy developed by the displaced water molecules as compared to that lost as a result of dye uptake. Negative values of $\Delta G$ indicate that the RR239 dye adsorption by chitosan $8 \mathrm{~B}$ adsorbents is a spontaneous process and more favorable process at higher temperature. The increase in the adsorption capacities of Chitosan $8 \mathrm{~B}$ at higher temperatures may be attributed to the enhanced mobility and penetration of dye molecules within the adsorbent porous structures by overcoming the activation energy barrier and enhancing the rate of intraparticle diffusion [48].

\section{Conclusion}

In the present study, RR239 dye adsorption onto chitosan 8B was investigated in an aqueous solution. The effect of working parameters such as solution $\mathrm{pHs}$, initial dye concentrations, ionic strengths and temperatures on the adsorption of RR239 was investigated. The obtained results suggested that all the parameters had a strong effect on the adsorption kinetics and equilibrium adsorption of RR239 onto the adsorbent. The batch adsorption kinetics was well explained by pseudo second-order model while intraparticle diffusion performed significant role in the rate limiting step. The batch adsorption kinetic profiles were absolutely reproduced by numerical analysis based on the pseudo second-order kinetic model in Equation (4) using the values of $k_{2}$ and $q_{\text {e(cal) }}$ given in Table 1. Adsorption isotherms were fitted well with the Langmuir model rather than the Freundlich, Temkin and Dubinin-Radushkevich models. The maximum RR239 dye adsorption capacity of chitosan $8 \mathrm{~B}$ was found to be $163.93 \mu \mathrm{mol} / \mathrm{g}$ at $45^{\circ} \mathrm{C}$. Thermodynamic parameters showed that the RR239 dye adsorption onto chitosan $8 \mathrm{~B}$ was spontaneous endothermic physisorption process. The significant amount (89\%) of RR239 dye was released from dye-loaded chitosan in $0.1 \mathrm{M}$ $\mathrm{NaOH}$ solution ( $\mathrm{pH}$ 12.5) and the chitosan flakes could be reused. The present works confirm that the easily obtainable chitosan $8 \mathrm{~B}$ can be utilized as an efficient biosorbent to remove reactive dyes from industrial wastewater.

\section{Acknowledgements}

The authors have declared no conflict of interest. We are indebted to the authority of the Ministry of Science and Technology, Government of the People's Republic of Bangladesh for giving a research grant to carry out this work (FY 2013-2014). We gratefully acknowledge the support by the Alexander von Humboldt Foundation (George Forster Research Fellowship to T.K.S at Göet- 
tingen University, Germany where he has taken the diffuse reflectance electronic absorption spectra of solid samples). Authors are thankful to Prof. Yoshinobu Fukumori and Prof. Hideki Ichikawa (Kobe Gakuin University, Kobe, Japan) for providing the sample of chitosan $8 \mathrm{~B}$ and measuring its particle size.

\section{Conflicts of Interest}

The authors declare no conflicts of interest regarding the publication of this paper.

\section{References}

[1] Ngah, W.S.W., Ariff, N.F.M., Hashim, A. and Hanafiah, M.A.K.M. (2010) Malachite Green Adsorption onto Chitosan Coated Bentonite Beads: Isotherms, Kinetics and Mechanism. Clean-Soil, Air, Water, 38, 394-400. https://doi.org/10.1002/clen.200900251

[2] Saha, T.K., Frauendorf, H., John, M., Dechert, S. and Meyer, F. (2013) Efficient Oxidative Degradation of Azo Dyes by a Water-Soluble Manganese Porphyrin Catalyst. ChemCatChem, 5, 796-805. https://doi.org/10.1002/cctc.201200475

[3] Weisburger, J.H. (2002) Comments on the History and Importance of Aromatic and Heterocylic Amines in Public Health. Mutation Research, 506-507, 9-20. https://doi.org/10.1016/S0027-5107(02)00147-1

[4] Ali, I. and Gupta, V.K. (2006) Advances in Water Treatment by Adsorption Technology. Nature Protocols, 1, 2661-2667. https://doi.org/10.1038/nprot.2006.370

[5] Ali, I. (2012) New Generation Adsorbents for Water Treatment. Chemical Reviews, 112, 5073-5091. https://doi.org/10.1021/cr300133d

[6] Ai, L., Zhang, C., Liao, F., Wang, Y., Li, K., Meng, L. and Jiang, J. (2011) Removal of Methylene Blue from Aqueous Solution with Magnetite Loaded Multi-Wall Carbon Nanotube: Kinetic, Isotherm and Mechanism Analysis. Journal of Hazardous Materials, 198, 282-290. https://doi.org/10.1016/j.jhazmat.2011.10.041

[7] Gomez, V., Larrechi, M.S. and Callao, M.P. (2007) Kinetic and Adsorption Study of Acid Dye Removal Using Activated Carbon. Chemosphere, 69, 1151-1158. https://doi.org/10.1016/j.chemosphere.2007.03.076

[8] Thamaraiselvan, C. and Noel, M. (2015) Membrane Processes for Dye Wastewater Treatment: Recent Progress in Fouling Control. Critical Reviews in Environmental Science and Technology, 45, 1007-1040. https://doi.org/10.1080/10643389.2014.900242

[9] Olad, A., Ghadim, A.R.A., Dorraji, M.S.S. and Rasoulifard, M.H. (2010) Removal of the Alphazurine FG Dye from Simulated Solution by Electrocoagulation. Clean-Soil, Air, Water, 38, 401-408. https://doi.org/10.1002/clen.200900213

[10] Khadhraoui, M., Trabelsi, H., Ksibi, M., Bouguerra, S. and Elleuch, B. (2009) Discoloration and Detoxification of a Congo Red Dye Solution by Means of Ozone Treatment for a Possible Water Reuse. Journal of Hazardous Materials, 161, 974-981. https://doi.org/10.1016/j.jhazmat.2008.04.060

[11] Sires, I., Guivarch, E., Oturan, N. and Oturan, M.A. (2008) Efficient Removal of Triphenylmethane Dyes from Aqueous Medium by in Situ Electrogenerated Fenton's Reagent at Carbon-Felt Cathode. Chemosphere, 72, 592-600. https://doi.org/10.1016/j.chemosphere.2008.03.010

[12] Kim, D.S. and Park, Y.S. (2008) Comparison Study of Dyestuff Wastewater Treat- 
ment by the Coupled Photocatalytic Oxidation and Biofilm Process. Chemical Engineering Journal, 139, 256-263. https://doi.org/10.1016/j.cej.2007.07.095

[13] Mishra, S. and Maiti, A. (2018) The Efficacy of Bacterial Species to Decolourise Reactive Azo, Anthroquinone and Triphenylmethane Dyes from Wastewater: A Review. Environmental Science and Pollution Research, 25, 8286-8314. https://doi.org/10.1007/s11356-018-1273-2

[14] Martins, T.D., Schimmel D, das Santos, J.B.O. and da Silva, E.A. (2013) Reactive Blue 5G Adsorption onto Activated Carbon: Kinetics and Equilibrium. Journal of Chemical \& Engineering Data, 58, 106-114. https://doi.org/10.1021/je300946j

[15] Nemr, A.E., Abdelwahab, O., EI-Sikaily, A. and Khaled, A. (2009) Removal of Direct Blue-86 from Aqueous Solution by New Activated Carbon Developed from Orange Peel. Journal of Hazardous Materials, 161, 102-110. https://doi.org/10.1016/j.jhazmat.2008.03.060

[16] Sanchez, N., Benedetti, T.M., Vazquez, M., de Torresi, S.I.C. and Torresi, R.M. (2012) Kinetic and Thermodynamic Studies on the Adsorption of Reactive Red 239 by Carra Sawdust Treated with Formaldehyde. Adsorption Science \& Technology, 30, 881-899. https://doi.org/10.1260/0263-6174.30.10.881

[17] Banaei, A., Yaychi, M.F., Karimi, S., Vojoudi, H., Namazi, H., Badiei, A. and Pourbasheer, E. (2018) 2,2'-(Butane-1,4-diylbis(oxy))dibenzaldehyde Cross-Linked Magnetic Chitosan Nanoparticles as a New Adsorbent for the Removal of Reactive Red 239 from Aqueous Solutions. Materials Chemistry and Physics, 212, 1-11. https://doi.org/10.1016/j.matchemphys.2018.02.036

[18] Caglar, E., Donari, Y.O., Sinag, A., Birogul, I., Bilge, S., Aydincak, K. and Pliekhov, O. (2018) Adsorption of Anionic and Cationic Dyes on Biochars, Produced by Hydrothermal Carbonization of Waste Biomass: Effect of Surface Functionalization and Ionic Strength. Turkish Journal of Chemistry, 42, 86-99.

https://doi.org/10.3906/kim-1704-12

[19] Banerjee, S. and Chattopadhyaya, M.C. (2017) Adsorption Characteristics for the Removal of a Toxic Dye Tartazine from Aqueous Solutions by a Low Cost Agricultural By-Product. Arabian Journal of Chemistry, 10, S1629-S1638. https://doi.org/10.1016/j.arabjc.2013.06.005

[20] Karmaker, S., Uddin, M.N., Ichikawa, H., Fukumori, Y. and Saha, T.K. (2015) Adsorption of Reactive Orange 13 onto Jackfruit Seed Flakes in Aqueous Solution. Journal of Environmental Chemical Engineering, 3, 583-592. https://doi.org/10.1016/j.jece.2014.09.010

[21] Bazrafshan, E., Mostafapour, F.K., Hosseini, A.R., Khorshid, A.R. and Mahvi, A.H. (2013) Decolorisation of Reactive Red 120 Dye by Using Single-Walled Carbon Nanotubes in Aqueous Solutions. Journal of Chemistry, 2013, Article ID: 938374. doi: http://dx.doi.org/10.1155/2013/938374

[22] Shirmardi, M., Mesdaghinia, A.R., Mahvi, A.H., Nasseri, S. and Nabizadeh, R. (2012) Kinetics and Equilibrium Studies on Adsorption of Acid Red 18 (Azo-Dye) Using Multiwall Carbon Nanotubes (MWCNTs) from Aqueous Solution. E-Journal of Chemistry, 9, 2371-2383. https://doi.org/10.1155/2012/541909

[23] Ngaha, W.S.W., Teonga, L.C. and Hanafiaha, M.A.K.M. (2011) Adsorption of Dyes and Heavy Metal Ions by Chitosan Composites: A Review. Carbohydrate Polymers, 83, 1446-1456. https://doi.org/10.1016/j.carbpol.2010.11.004

[24] Wu, F.C., Tseng, R.L. and Juang, R.S. (2010) A Review and Experimental Verification of Using Chitosan and Its Derivatives as Adsorbents for Selected Heavy Metals. Journal of Environmental Management, 91, 798-806. 
https://doi.org/10.1016/j.jenvman.2009.10.018

[25] Chiou, M.S. and Li, H.Y. (2003) Adsorption Behavior of Reactive Dye in Aqueous Solution on Chemical Crosslinked Chitosan Beads. Chemosphere, 50, 1095-1105. https://doi.org/10.1016/S0045-6535(02)00636-7

[26] Karmaker, S., Sen, T. and Saha, T.K. (2015) Adsorption of Reactive Yellow 145 onto Chitosan in Aqueous Solution: Kinetic Modeling and Thermodynamic Analysis. Polymer Bulletin, 72, 1879-1897. https://doi.org/10.1007/s00289-015-1378-4

[27] Saha, T.K., Bhoumik, N.C., Karmaker, S., Ahmed, M.G., Ichikawa, H. and Fukumori, Y. (2011) Adsorption Characteristics of Reactive Black 5 from Aqueous Solution onto Chitosan. Clean-Soil, Air, Water, 39, 984-993. https://doi.org/10.1002/clen.201000315

[28] Chiou, M.S. and Li, H.Y. (2002) Equilibrium and Kinetic Modeling of Adsorption of Reactive Dye on Cross-Linked Chitosan Beads. Journal of Hazardous Materials, 93, 233-248. https://doi.org/10.1016/S0304-3894(02)00030-4

[29] Hasan, M., Ahmad, A.L. and Hameed, B.H. (2008) Adsorption of Reactive Dye onto Cross-Linked Chitosan/Oil Palm Ash Composite Beads. Chemical Engineering Journal, 136, 164-172. https://doi.org/10.1016/j.cej.2007.03.038

[30] Bhattacharyya, K.G. and Sharma, A. (2003) Adsorption Characteristics of the Dye, Brilliant Green, on Neem Leaf Powder. Dyes and Pigments, 57, 211-222. https://doi.org/10.1016/S0143-7208(03)00009-3

[31] Lagergren, S.Y. (1898) Zur theorie der sogenannten adsorption geloster stoffe. Kungliga Svenska Vetenskapsakad, Stockholm, 24, 1-39.

[32] McKay, G. and Ho, Y.S. (1999) Pseudo-Second Order Model for Sorption Processes. Process Biochemistry, 34, 451-465. https://doi.org/10.1016/S0032-9592(98)00112-5

[33] Elovich, S.Y. and Larinov, O.G. (1962) Theory of Adsorption from Solutions of Non Electrolytes on Solid (I) Equation Adsorption from Solutions and the Analysis of Its Simplest Form, (II) Verification of the Equation of Adsorption Isotherm from Solutions. Otdelenie Khimicheskikh Nauk, 2, 209-216.

[34] Weber, W.J. and Morris, J.C. (1963) Kinetics of Adsorption on Carbon from Solution. American Society of Civil Engineers, 89, 31-60.

[35] Eren, E., Cubuk, O., Ciftci, H., Eren, B. and Caglar, B. (2010) Adsorption of Basic Dye from Aqueous Solutions by Modified Sepiolite: Equilibrium, Kinetics and Thermodynamics Study. Desalination, 252, 88-96. https://doi.org/10.1016/j.desal.2009.10.020

[36] Wu, C.H. (2007) Adsorption of Reactive Dye onto Carbon Nanotubes: Equilibrium, Kinetics and Thermodynamics. Journal of Hazardous Materials, 144, 93-100. https://doi.org/10.1016/j.jhazmat.2006.09.083

[37] Dogan, M., Alkan, M., Demirbas, O., Ozdemir, Y. and Ozmetin, C. (2006) Adsorption Kinetics of Maxilon Blue GRL onto Sepiolite from Aqueous Solutions. Chemical Engineering Journal, 124, 89-101. https://doi.org/10.1016/j.cej.2006.08.016

[38] Eren, E. (2010) Adsorption Performance and Mechanism in Binding of Azo Dye by Raw Bentonite. Clean-Soil, Air, Water, 38, 758-763. https://doi.org/10.1002/clen.201000060

[39] Gupta, K.V., Srivastava, S.K. and Mohan, D. (1997) Equilibrium Uptake, Sorption Dynamics, Process Optimization and Column Operation for the Removal and Recovery of Malachine Green from Wastewater Using Activated Carbon and Activated Slag. Industrial \& Engineering Chemistry Research, 36, 2207-2218. https://doi.org/10.1021/ie960442c

[40] Freundlich, H. (1906) Adsorption Solution. Zeitschrift für Physikalische Chemie, 
57, 384-470.

[41] Temkin, M.I. and Pyzhev, V. (1940) Kinetics of Ammonia Synthesis on Promoted Iron Catalyst. Acta Physicochimica URSS, 12, 327-356.

[42] Inyinbor, A.A., Adekola, F.A. and Olatunji, G.A. (2016) Kinetics, Isotherms and Thermodynamic Modeling of Liquid Phase Adsorption of Rhodamine B Dye onto Raphia hookerie Fruit Epicarp. Water Resources and Industry, 15, 14-27. https://doi.org/10.1016/j.wri.2016.06.001

[43] Langmuir, I. (1918) Adsorption of Gases on Plain Surfaces of Glass Mica Platinum. Journal of the American Chemical Society, 40, 1361-1403. https://doi.org/10.1021/ja02242a004

[44] Hall, K.R., Eagleton, L.C., Acrivers, A. and Vermenlem, T. (1966) Pore- and Solid-Diffusion Kinetics in Fixed-Bed Adsorption under Constant Pattern Conditions. Industrial \& Engineering Chemistry Fundamentals, 5, 212-223. https://doi.org/10.1021/i160018a011

[45] Alver, E. and Metin, A.Ü. (2012) Anionic Dye Removal from Aqueous Solution Using Modified Zeolite: Adsorption Kinetics and Isotherm Studies. Chemical Engineering Journal, 200-202, 59-67. https://doi.org/10.1016/j.cej.2012.06.038

[46] Ozdemir, O., Armagan, B., Turan, M. and Celik, M.S. (2004) Comparison of the Adsorption Characteristics of Azo-Reactive Dyes on Mezoporous Minerals. Dyes and Pigments, 62, 49-60. https://doi.org/10.1016/j.dyepig.2003.11.007

[47] Karadag, D., Turan, M., Akgul, E., Tok, S. and Faki, A. (2007) Adsorption Equilibrium and Kinetics of Reactive Black 5 and Reactive Red 239 in Aqueous Solution onto Surfactant-Modified Zeolite. Journal of Chemical \& Engineering Data, 52 1615-1620. https://doi.org/10.1021/je7000057

[48] Calvete, T., Lima, E.C., Cardoso, N.F., Dias, S.L.P. and Ribeiro, E.S. (2010) Removal of Brilliant Green Dye from Aqueous Solutions Using Homemade Activated Carbons. Clean-Soil, Air, Water, 38, 521-532. https://doi.org/10.1002/clen.201000027 